\title{
Tipos de Análise da Cultura Organizacional de Trompenaars (1 994) Predominantes na Área de Controladoria em Empresas Familiares do Ramo Têxtil
}

\author{
Vanderlei dos Santos ${ }^{1}$ \\ Ilse Maria Beuren ${ }^{2}$ \\ Nelson Hein ${ }^{3}$ \\ Ananias Francisco dos Santos ${ }^{4}$
}

\section{Resumo}

O estudo objetiva identificar os tipos de análise da cultura organizacional de Trompenaars (1994) predominantes na área de controladoria em empresas familiares do ramo têxtil. Realizou-se pesquisa descritiva, com abordagem qualitativa e quantitativa, por meio de um estudo multicasos. Os dados foram coletados através de entrevista com o controller das empresas. Em relação aos quatro tipos básicos de cultura sugeridos por Trompenaars (1994), conclui-se que não existe um tipo puro, mas há forte presença da cultura familiar entre as empresas pesquisadas nas dimensões Relação entre Empregados, Atitude em Relação à Autoridade, Formas de Mudanças, Formas de Motivação e Recompensa.

Palavras-chave: Cultura organizacional. Tipologia de Trompenaars. Controladoria.

\section{Introdução}

Aspectos comportamentais e culturais das organizações são temas amplamente pesquisados na área da Administração. Entretanto, o relacionamento

\footnotetext{
${ }^{1}$ Mestrando do Programa de Pós-Graduação em Ciências Contábeis da Universidade Regional de Blumenau - FURB. Endereço: Rua Antônio da Veiga, 140 - Sala D 202 - Bairro Victor Konder. CEP 89012-900 - Blumenau -SC - Brasil. E-mail: vs@al.furb.br.

${ }^{2}$ Doutora em Controladoria e Contabilidade pela FEA/USP. Professora do Programa de Pós-Graduação em Ciências Contábeis da Universidade Regional de Blumenau - FURB. Endereço: Rua Antônio da Veiga, 140 - Sala D 202 - Bairro Victor Konder. CEP $89012-900$ - Blumenau -SC-Brasil.E-mail: ilse@furb.br.

${ }^{3}$ Doutor em Engenharia de Produção pela EPS/UFSC. Professor do Programa de Pós-Graduação em Ciências Contábeis da Universidade Regional de Blumenau - FURB. Endereço: Rua Antônio da Veiga, 140 - Sala D 202 - Bairro Victor Konder. CEP $89012-900$ - Blumenau -SC-Brasil.E-mail: hein@furb.br.

${ }^{4}$ Mestrando do Programa de Pós-Graduação em Ciências Contábeis da Universidade Regional de Blumenau - FURB. Endereço: Rua Antônio da Veiga, 140 - Sala D 202 - Bairro Victor Konder. CEP 89012-900 - Blumenau -SC - Brasil. E-mail: prof.ananias@gmail.com. Artigo recebido em: 11/04/2010. Aceito em: 05/06/2010. Membro do Corpo Editorial Científico responsável pelo processo editorial: Rolando Juan Soliz Estrada.
} 
entre a cultura organizacional e as práticas contábeis nas empresas é um tema ainda pouco explorado nas áreas das Ciências Contábeis. Em algumas situações, o setor contábil de uma organização funciona de acordo com as necessidades culturais, as quais envolvem o ambiente onde a organização está inserida (TARIFA, 2008).

Tarifa (2007) pesquisou a relação entre a cultura organizacional e as práticas de controladoria de uma empresa de capital aberto da cidade de Londrina, estado do Paraná. As práticas de controladoria da empresa foram identificadas com base nas etapas de planejamento, controle e execução. Para a avaliação da cultura organizacional da controladoria da empresa, utilizou o Modelo de Valores Competitivos de Cameron e Quinn (1999), aplicado aos colaboradores das áreas administrativas, financeiras, contábeis e de custos. Concluiu que a cultura organizacional identificada por meio das estruturas de crenças e valores que sustenta as características da empresa influencia as práticas de controladoria na companhia de café solúvel, ficando visíveis as classificações atuais de cultura hierárquica e ideais de cultura de clã, segundo o modelo de Cameron e Quinn (1999).

Santos, Almeida e Crozatti (2007) pesquisaram o processo de institucionalização da área organizacional de controladoria e a influência da psicologia humana e da cultura organizacional. Trata-se de um ensaio fundamentado em pesquisa bibliográfica. Observaram que os indivíduos têm suas ações caracterizadas por processos psicológicos e fatores socioculturais, os quais exercem papel relevante na institucionalização da área organizacional da controladoria e para entender como são formadas as demais instituições nas organizações.

Freitag et al. (2008) investigaram como a cultura influencia a opção por práticas da contabilidade gerencial, especificamente na utilização de instrumentos como orçamento e custeio. Foram pesquisados dois arranjos produtivos locais (APLs). Aplicaram questionário em 43 grupos empresariais da Região Metropolitana de Curitiba e em 26 grupos empresariais localizados no Município de Terra Roxa, no Paraná. Verificaram que a busca de melhores resultados por meio de instrumentos contábeis para a gestão de custos e a utilização de orçamentos como forma de controle são características das empresas em que o gestor possui qualificação de nível superior na área de negócios. Também constataram que a cultura predominante em cada região é decisiva para a adoção das práticas de orçamento e custeio.

Observa-se nesses estudos que há relacionamento entre cultura e as práticas contábeis adotadas pelas organizações. Conforme Schneider (1996), 
a cultura da empresa é o elemento essencial para ela chegar ao sucesso organizacional, porque é em si que estão centrados seus valores, crenças, regras de funcionamento e procedimentos internos. As características culturais estão presentes em todos os setores das organizações, dentre eles, a área organizacional denominada controladoria.

Mosimann e Fisch (1999) visualizam a controladoria sob dois enfoques: a) como órgão administrativo, com missão, funções e princípios norteadores definidos no modelo de gestão do sistema empresa; b) como área do conhecimento humano, com fundamentos, conceitos, princípios e métodos advindos de outras ciências. No primeiro enfoque, a controladoria representa um órgão formalmente constituído na estrutura da empresa, com funções estabelecidas, tendo por finalidade garantir informações adequadas ao processo decisório. O segundo enfoque, como área do conhecimento humano, representa um conjunto de princípios, procedimentos e métodos das ciências da administração, economia, psicologia, estatística, contabilidade, no qual se ocupa da gestão econômica das empresas, com o objetivo de orientá-las para eficácia.

Há várias formas de se analisar a cultura no ambiente organizacional, chamadas de tipologias de cultura organizacional. Destaca-se neste estudo a tipologia de Trompenaars (1994), que sugere a existência de quatro tipos básicos de organizações: cultura familiar, cultura torre Eiffel, cultura míssil guiado e cultura incubadora. Esses tipos de culturas empresariais variam consideravelmente na forma como as empresas pensam e aprendem, como se modificam e motivam, recompensam e solucionam conflitos. Leal, Souza e Rocha (2008) investigaram as características mais preponderantes dos tipos de culturas propostos por Trompenaars (1994) de uma fábrica de fertilizantes situada no estado da Bahia. De acordo com os autores, a organização estudada evidenciou traços mais marcantes das culturas Torre Eiffel e Familiar e alguns traços da cultura Míssil Guiado e Incubadora.

Diante do exposto, elaborou-se a seguinte questão-problema: Quais os tipos culturais da tipologia de Trompenaars (1994) são predominantes na área organizacional controladoria em empresas familiares do ramo têxtil? Nesse intuito, o estudo objetiva identificar os tipos de análise da cultura organizacional de Trompenaars (1994) predominantes na área de controladoria em empresas familiares do ramo têxtil.

A pesquisa justifica-se por relacionar a cultura organizacional com a área de controladoria, tema que ainda requer mais estudos para desvendar 
os reflexos da cultura no funcionamento dessa área organizacional. Portanto, a pesquisa pretende contribuir para o conhecimento da relação da cultura e as práticas da controladoria em empresas. A motivação do estudo decorre do fato desse tipo de estudo não estar amplamente discutido no Brasil, podendo contribuir para maiores esclarecimentos.

O estudo está organizado em seis seções, iniciando com esta introdução. Na sequência, apresenta a plataforma teórica, com uma contextualização de cultura organizacional e a exposição da tipologia de Trompenaars. Após, demonstra o método e os procedimentos da pesquisa. Em seguida, apresenta os resultados da pesquisa efetuada em três empresas do ramo têxtil que possuem a área organizacional controladoria. Por fim, expõe as conclusões do estudo realizado e recomendações para futuras pesquisas sobre o tema investigado.

\section{Tipos de Análise da Cultura Organizacional Segundo Trompenaars (1994)}

Cultura organizacional é conceituada por Schein (1984, p. 93) como sendo "um conjunto de pressupostos básicos que determinado grupo inventou, descobriu ou desenvolveu ao aprender a lidar com os problemas de adaptação" ao meio externo e de integração e organização interna, e que funcionaram bem o suficiente para serem considerados válidos e ensinados aos novos membros como a maneira correta de perceber, pensar e agir em relação a esses problemas.

De acordo com Trompenaars (1994), a cultura é a maneira por meio da qual um grupo de pessoas resolve problemas. Ela se apresenta em diferentes níveis. No nível mais alto, encontra-se a cultura de uma sociedade nacional ou regional, francesa ou europeia, ocidental versus oriental. Em seguida, consta a cultura empresarial ou organizacional, que é a forma como as atitudes são expressas dentro de uma organização específica. Por último, há a cultura de certos departamentos das organizações, como marketing, controladoria, pesquisa e desenvolvimento. A tendência das pessoas de departamentos é compartilhar determinadas orientações profissionais e éticas.

Há várias formas de se analisar a cultura no ambiente organizacional, denominadas de tipologias de cultura organizacional. O presente estudo foi 
baseado nos estudos de Trompenaars (1994), o qual é abordado nos tópicos seguintes. Trompenaars (1994) propôs primeiramente uma análise cultural inter-relações, e, em segundo lugar, uma tipologia para análise organizacional, sendo esta o foco deste estudo. Para construir uma tipologia de análise da cultura organizacional, isto é, voltada para o estudo de organizações e não de nações, o autor sugere o uso de duas dimensões: a) igualdade versus hierarquia; e b) orientações em relação às pessoas versus tarefas.

Conforme Trompenaars (1994, p. 144),

[...] essas dimensões permitem definir quatro tipos de culturas empresariais, que variam consideravelmente na forma como as empresas pensam e aprendem, como se modificam e motivam, recompensam e solucionam conflitos.

Os quatros tipos podem ser descritos da seguinte forma: a Família (cultura voltada ao poder), a Torre Eiffel (cultura orientada à função), o Míssil Guiado (cultura voltada ao projeto) e a Incubadora (cultura voltada à satisfação).

Conforme Trompenaars (1994), a cultura familiar possui caráter pessoal com relações próximas, porém, é ao mesmo tempo hierárquica, tendo uma cultura voltada ao poder. Na cultura do tipo Torre Eiffel, as relações são impessoais e a hierarquia está baseada nos cargos e não nas pessoas. Na cultura míssil guiado, há mais igualdade entre as pessoas, porém, possui certo grau de impessoalidade, com ênfase nos objetivos estratégicos da organização. Já na cultura do tipo Incubadora, os objetivos organizacionais estão subordinados aos objetivos pessoais do grupo, trata-se de uma cultura mais igualitária e voltada à pessoa.

Trompenaars (1994, p. 144) ressalta que

[...] esses tipos de culturas empresariais são "ideais". Na prática, os tipos são misturados ou sobrepostos por uma cultura dominante. Entretanto, essa separação é útil para explorar a base de cada tipo em termos de como os empregados aprendem, mudam, solucionam conflitos, recompensam, motivam, etc.

As características das quatro culturas empresariais propostas por Trompenaars (1994) estão sintetizadas no Quadro 1. 


\begin{tabular}{|c|c|c|c|c|}
\hline & Família & Torre Eiffel & Míssil Guiado & Incubadora \\
\hline $\begin{array}{l}\text { Relações } \\
\text { entre empre- } \\
\text { gados. }\end{array}$ & $\begin{array}{l}\text { Relações difusas } \\
\text { com o todo } \\
\text { orgânico ao qual } \\
\text { está relacionado. }\end{array}$ & $\begin{array}{l}\text { Papel específico } \\
\text { no sistema } \\
\text { mecânico de } \\
\text { interações neces- } \\
\text { sárias. }\end{array}$ & $\begin{array}{l}\text { Tarefas específicas } \\
\text { no sistema } \\
\text { cibernético, } \\
\text { visando objetivos } \\
\text { compartilhados. }\end{array}$ & $\begin{array}{l}\text { Difusa, relações } \\
\text { espontâneas } \\
\text { crescendo a } \\
\text { partir do } \\
\text { processo } \\
\text { criativo com- } \\
\text { partilhado. }\end{array}$ \\
\hline $\begin{array}{l}\text { Atitude em } \\
\text { relação à } \\
\text { autoridade. }\end{array}$ & $\begin{array}{l}\text { Status atribuído } \\
\text { aos pais que são } \\
\text { próximose } \\
\text { poderosos. }\end{array}$ & $\begin{array}{l}\text { Status atribuído } \\
\text { aos papéis superi- } \\
\text { ores que são } \\
\text { distantes, embora } \\
\text { poderosos. }\end{array}$ & $\begin{array}{l}\text { O status alcançado } \\
\text { por meio dos } \\
\text { membros do grupo } \\
\text { do projeto, que } \\
\text { contribuem para as } \\
\text { metas almejadas. }\end{array}$ & $\begin{array}{l}\text { Status alcança- } \\
\text { do pelos } \\
\text { indivíduos que } \\
\text { são exemplos } \\
\text { de criatividade } \\
\text { e crescimento. }\end{array}$ \\
\hline $\begin{array}{l}\text { Formas de } \\
\text { pensamento } \\
\text { aprendizado. }\end{array}$ & $\begin{array}{l}\text { Intuitiva, } \\
\text { eholística, lateral e } \\
\text { corretora de erros. }\end{array}$ & $\begin{array}{l}\text { Lógica, analítica, } \\
\text { vertical e racional- } \\
\text { mente eficiente. }\end{array}$ & $\begin{array}{l}\text { Centrada em } \\
\text { problemas, } \\
\text { profissional, } \\
\text { prática, } \\
\text { interdisciplinar. }\end{array}$ & $\begin{array}{l}\text { Voltada ao } \\
\text { processo, } \\
\text { criativa, ad hoc } \\
\text { e inspiracional. }\end{array}$ \\
\hline $\begin{array}{l}\text { Atitude em } \\
\text { relação às } \\
\text { pessoas. }\end{array}$ & $\begin{array}{l}\text { Membros da } \\
\text { família. }\end{array}$ & $\begin{array}{l}\text { Recursos huma- } \\
\text { nos. }\end{array}$ & Especialistas. & Cocriadores. \\
\hline $\begin{array}{l}\text { Formas de } \\
\text { mudança. }\end{array}$ & $\begin{array}{l}\text { O "pai" muda o } \\
\text { curso. }\end{array}$ & $\begin{array}{l}\text { Modifica regras e } \\
\text { procedimentos. }\end{array}$ & $\begin{array}{l}\text { Troca de objetivos } \\
\text { à medida que a } \\
\text { meta se desloca. }\end{array}$ & $\begin{array}{l}\text { Improvisa e } \\
\text { inova. }\end{array}$ \\
\hline $\begin{array}{l}\text { Formas de } \\
\text { motivação e } \\
\text { recompensa. }\end{array}$ & \begin{tabular}{|l|} 
Satisfação \\
intrínseca em ser \\
amado e respeita- \\
do.
\end{tabular} & $\begin{array}{l}\text { Promoção a uma } \\
\text { posição melhor, } \\
\text { papel mais amplo. }\end{array}$ & $\begin{array}{l}\text { Remuneração ou } \\
\text { crédito pelo } \\
\text { desempenho e } \\
\text { problemas resolvi- } \\
\text { dos. }\end{array}$ & $\begin{array}{l}\text { Participa do } \\
\text { processo de } \\
\text { criação de } \\
\text { novas realida- } \\
\text { des. }\end{array}$ \\
\hline $\begin{array}{l}\text { Reprovação } \\
\text { e resolução } \\
\text { de conflitos. }\end{array}$ & \begin{tabular}{|l|} 
Administração \\
por aspectos \\
subjetivos. Dar a \\
outra face, limpar \\
a barra dos \\
outros, não \\
perder o jogo do \\
poder.
\end{tabular} & $\begin{array}{l}\text { Administração por } \\
\text { descrição do } \\
\text { trabalho. A crítica } \\
\text { é acusação de } \\
\text { irracionalismo, a } \\
\text { não ser que } \\
\text { existam procedi- } \\
\text { mentos para } \\
\text { arbitrar o conflito. }\end{array}$ & $\begin{array}{l}\text { Administração por } \\
\text { objetivos. } \\
\text { Construtiva e } \\
\text { relacionada à } \\
\text { tarefa apenas, só } \\
\text { depois admite o } \\
\text { erro e corrige } \\
\text { rapidamente. }\end{array}$ & $\begin{array}{l}\text { Administração } \\
\text { pelo entusias- } \\
\text { mo. Deve } \\
\text { aprimorar a } \\
\text { criatividade, e } \\
\text { não negá-la. }\end{array}$ \\
\hline
\end{tabular}

Quadro 1: As características dos tipos culturais de Trompenaars

Fonte: Trompenaars (1994, p. 166) 
Na sequência, apresentam-se com maiores detalhes as características dos quatro tipos de cultura organizacional propostos por Trompenaars (1994).

\subsection{Cultura Familiar}

Neste tipo, a cultura é voltada ao poder: o líder é considerado um pai carinhoso que sabe mais do que seus subordinados, o que deve ser feito e o que é bom para eles. A ideia é sempre fazer mais do que a obrigação imposta por um contrato ou acordo. A relação com a empresa é de devoção a longo prazo. O líder da cultura Familiar cria o padrão, define o tom, serve de modelo para a postura apropriada dentro da empresa e espera que os subordinados estejam sintonizados "no mesmo comprimento da onda", sabendo intuitivamente o que é necessário (TROMPENAARS, 1994).

As relações tendem a ser difusas. O pai ou o irmão mais velho influencia todas as situações, independente de ter conhecimento do problema ou não, do evento ocorrer no trabalho, na cantina ou no caminho para casa $e$ até de existir alguém melhor qualificado. A empresa se preocupa com os funcionários, com o fato de seus salários serem suficientes para que vivam adequadamente (TROMPENAARS, 1994).

As decisões neste tipo de cultura devem ser tomadas pela pessoa de maior autoridade presente. Também quase não há limite para as responsabilidades da empresa em relação aos seus funcionários. Isso se estende até mesmo ao local onde moram. Há a ideia de quanto mais a empresa fizer pela família de seus subordinados, mais sua família desejará que o responsável pelo seu sustento faça pela empresa. A cultura familiar está mais interessada no conhecimento intuitivo do que no racional, mais preocupada com o desenvolvimento das pessoas do que com seu aproveitamento ou utilização. A pessoa que está fazendo alguma coisa é mais importante do que o que está sendo feito (TROMPENAARS, 1994).

Como os membros da família apreciam suas relações, podem se sentir mais motivados pela apreciação do que por dinheiro. Dificilmente se adaptam à remuneração pelo desempenho ou a qualquer outra forma de motivação que ameace os laços familiares. A resolução do conflito depende da habilidade do líder. As críticas raramente são expressas publicamente. O modelo familiar dá baixa prioridade à eficiência (fazer certo as coisas), mas alta prioridade à eficácia (fazer as coisas certas) (TROMPENAARS, 1994). 
Machado e Carvalho (2008) resumem este tipo de cultura mencionando que se trata de uma cultura pessoal, com relações próximas e diretas, mas, ao mesmo tempo, hierárquica. Esta cultura é voltada ao poder exercido pelo líder considerado como um pai experiente, responsável e bondoso.

\subsection{Cultura Torre Eiffel}

Neste tipo, a cultura é orientada à função. Sua hierarquia é muito diferente da utilizada na familiar. Os níveis mais altos possuem a função clara $e$ demonstrável de manter os níveis inferiores unidos. O objetivo racional da empresa é transmitido ao subordinado por meio do chefe: este possui autoridade legal para dizer o que aquele deve fazer, cujo contrato de serviços, explícita ou implicitamente, obriga-o a trabalhar de acordo com essas instruções. O trabalho é definido formalmente e sua execução é avaliada de acordo com essa definição. Pouco é deixado a cargo da sorte ou das idiossincrasias dos indivíduos (TROMPENAARS, 1994).

Machado e Carvalho (2008) enfatizam que se refere ao tipo de organização caracterizado como burocracia formal, com divisão de trabalho, no qual cada um é responsável pela execução de seu papel. Há um extremo racionalismo, de acordo com métodos e regras, e a hierarquia está baseada nos cargos e não nas pessoas.

Quase tudo o que a cultura Familiar aceita, a Torre Eiffel rejeita. As relações pessoais são propensas a atrapalhar os julgamentos, criar favoritismos, multiplicar exceções às regras e obscurecer as fronteiras claras entre funções e responsabilidades. Todas as funções em todos os níveis da hierarquia são descritas e classificadas segundo sua dificuldade, complexidade e responsabilidade, e existe um salário associado a cada uma delas. Ao considerar candidatos para ocupação de determinada vaga, o departamento de pessoal tratará todos de forma semelhante e neutra, comparará as habilidades e aptidões de cada pessoa aos requisitos do cargo e o dará a quem melhor se adequar à função. Igual procedimento é seguido nas avaliações e promoções (TROMPENAARS, 1994).

As pessoas são consideradas semelhantes aos recursos de capital e caixa. Pessoas com qualificações conhecidas podem ser planejadas, programadas, utilizadas e recarregadas por conjunto de técnicas, como qualquer entidade física. A função do planejamento da mão de obra, centros de avaliação, sistemas de avaliação, esquemas de treinamento e rotatividade de car- 
gos é ajudar na classificação e produzir recursos para a adequação às funções conhecidas (TROMPENAARS, 1994).

A mudança na Torre Eiffel é efetuada por meio de regras de mudança. Junto com qualquer alteração do propósito da empresa, devem ocorrer mudanças nas exigências formais feitas aos empregados. A mudança na cultura do tipo Torre Eiffel é imensamente complexa e leva muito tempo. É preciso reescrever manuais, modificar procedimentos, alterar descrições de cargos, reconsiderar promoções, reavaliar qualificações. Essas empresas resistem à mudança e, quando ela se torna inevitável, sofrem transtornos como consequência. Os conflitos são considerados irracionais, patologias do procedimento organizado, ofensas contra a eficiência. As críticas e reclamações são normalmente canalizadas e tratadas por meio de outras regras e procedimentos para levantamento dos fatos (TROMPENAARS, 1994).

\subsection{Cultura Míssil Guiado}

Neste tipo, a cultura é voltada ao projeto. Caracteriza-se por ser igualitária, impessoal e voltada à tarefa. O racional nesta cultura está nos fins. É preciso fazer todo possível para manter seu intento estratégico e alcançar seu objetivo. A cultura do míssil guiado é voltada às tarefas, tipicamente executadas por equipes ou grupos de projetos. Difere da cultura funcional porque os trabalhos executados pelos membros não são fixados com antecedência. Eles devem fazer o que é preciso para concluir uma tarefa (TROMPENAARS, 1994).

As culturas do tipo Míssil Guiado são caras, porque os profissionais são caros. Os grupos tendem a ser temporários; as relações possuem a mesma duração do projeto e são altamente instrumentais no que se refere a concluílo. O critério de valor humano na cultura do tipo Míssil Guiado é como você se sai e até que ponto contribui para o resultado final desejado por todos. Na verdade, todos os membros do grupo compartilham a resolução dos problemas (TROMPENAARS, 1994).

Frequentemente a avaliação é feita pelos colegas ou subordinados, $e$ não por alguém que ocupa uma posição mais alta na hierarquia. A mudança ocorre rapidamente na cultura do tipo míssil guiado. A meta se movimenta, novas metas surgem, novos grupos são formados, antigos grupos são dissolvidos. Frequentemente, os que passam de um grupo para outro também passam de um trabalho para outro, de forma que a rotatividade tende a ser alta 
e a lealdade à profissão e ao projeto é maior do que a lealdade à empresa. Em muitos aspectos, a cultura do tipo míssil guiado é a antítese da cultura familiar, na qual os laços são próximos e as ligações são duradouras e envolvem profunda afeição (TROMPENAARS, 1994).

A motivação tende a ser intrínseca, isto é, os membros da equipe se entusiasmam, se identificam e lutam pelo produto final. Esta cultura tende a ser individualista, porque permite que uma ampla variedade de pessoas com especializações diferentes trabalhem juntas temporariamente. Os rostos estão sempre mudando. Apenas a busca das linhas de desenvolvimento pessoal escolhidas é constante. A administração por objetivos é a linguagem falada e as pessoas são remuneradas pelo desempenho (TROMPENAARS, 1994).

No geral, constata-se que neste tipo de organização há mais igualdade entre as pessoas do que nas culturas tipo Torre Eiffel, porém, a ela se assemelha em seu grau de impessoalidade. O racionalismo desta cultura, ao contrário da Torre Eiffel, que enfatiza os cargos, ressalta os objetivos estratégicos da organização. Assim, os indivíduos trabalham em grupos, mas sem roteiros nem procedimentos pré-definidos, ou seja, devem agir como a situação exigir, contanto que atinjam suas metas (MACHADO; CARVALHO, 2008).

\subsection{Cultura Incubadora}

Neste tipo, a cultura é voltada à satisfação. Baseia-se na ideia existencial de que as empresas são secundárias à satisfação dos indivíduos. As funções das pessoas na incubadora são cruciais. Elas estão lá para confirmar, criticar, desenvolver, encontrar recursos e ajudar a concluir o produto ou serviço inovador (TROMPENAARS, 1994).

Geralmente, essas empresas são empreendedoras ou fundadas por uma equipe criativa que saiu de uma empresa maior, um pouco antes do fechamento das portas. Como são individualistas, essas pessoas não são limitadas pela lealdade à empresa. Possuem uma estrutura e hierarquia mínima. Essa autoridade, de fazer com que os indivíduos executem comandos, é estritamente pessoal. Geralmente as incubadoras operam em um ambiente de intenso compromisso emocional (TROMPENAARS, 1994).

Frequentemente, a motivação é sincera, intrínseca e intensa. Há uma competição quanto a contribuir com o surgimento de algo novo. Todos querem colocar as mãos no negócio. Não há grande preocupação com a segurança pessoal e poucos querem se aproveitar ou ficar de fora do processo 
criativo em expansão. A liderança, na Incubadora, é conquistada, e não atribuída. Os conflitos são resolvidos pela divisão do grupo ou pela tentativa de propostas alternativas, a fim de verificar qual funciona melhor (TROMPENAARS, 1994).

Em síntese, as organizações da cultura Incubadora moldam-se com o objetivo final de possibilitar a realização pessoal de seus indivíduos, isto é, os objetivos organizacionais estão subordinados aos objetivos pessoais do grupo. Essas organizações são ao mesmo tempo pessoais e igualitárias, isto é, são voltadas para as pessoas, mas todas as pessoas são vistas como iguais, sem regalias ou preconceitos individuais (MACHADO; CARVALHO, 2008).

Trompenaars (1994) ressalta que as empresas não são totalmente enquadráveis em uma das tipologias propostas, mas tendem a se apresentar como uma mistura das características de cada tipologia, porém com maior intensidade de um tipo específico. Afirma que as empresas bem-sucedidas utilizam características de todos os tipos e lutam incessantemente para conciliálas. Conforme o autor, as empresas menores, onde quer que estejam localizadas, são mais propensas a tomar a forma Familiar e de Incubadora. As empresas maiores, que precisam de estrutura coerente, são mais propensas a optar pela Torre Eiffel ou Míssil Guiado.

\section{Método e Técnicas da Pesquisa}

O presente estudo foi desenvolvido por meio de pesquisa descritiva com abordagem qualitativa e quantitativa. Conforme Cervo e Bervian (1996, p. 66), "a pesquisa descritiva observa, analisa e correlaciona fatos ou fenômenos (variáveis) sem manipulá-los". Afirmam ainda que a pesquisa descritiva "procura descobrir, com a previsão possivel, a frequência com que um fenômeno ocorre, sua relação e conexão com outros, sua natureza e características".

Abordagem qualitativa foi utilizada na primeira etapa da pesquisa, para decodificar as entrevistas realizadas. De acordo com Richardson (1999), a pesquisa qualitativa descreve a complexidade de determinado problema, analisa a interação de certas variáveis, compreende e classifica processos dinâmicos vividos por grupos sociais. Destaca que ela pode contribuir no processo de mudança de determinado grupo e possibilita, em maior nível de profundidade, o entendimento das particularidades do comportamento dos indivíduos. 
Na segunda etapa da pesquisa, foi adotada a abordagem quantitativa para o agrupamento dos dados conforme as dimensões dos tipos de cultura propostos por Trompenaars (1994) e a identificação da tipologia de cultura prevalecente nas empresas pesquisadas. $\mathrm{O}$ método quantitativo

[...] representa, em princípio, a intenção de garantir a precisão dos resultados, evitar distorções de análise e interpretação, possibilitando, consequentemente, uma margem de segurança quanto às inferências (RICHARDSON, 1999, p. 70).

A pesquisa descritiva foi realizada por meio de um estudo multicasos. Conforme Triviños (1987), o estudo multicasos diferencia-se do estudo comparativo de casos por propiciar ao pesquisador a possibilidade de estudar dois ou mais sujeitos, organizações, sem a necessidade de perseguir objetivos de natureza comparativa. Foram selecionadas três empresas do ramo têxtil, de origem familiar e que possuem o órgão controladoria formalmente constituído. As empresas são sociedades anônimas, duas delas (Empresas A e B) são de capital aberto e outra de capital fechado (Empresa $\mathrm{C}$ ), sendo que esta última é coligada de uma organização de capital aberto.

Optou-se por empresas familiares pelo fato de que um dos tipos de cultura da tipologia analisada refere-se à cultura Familiar. Essa opção poderia sugerir a exclusão das demais tipologias de análise da cultura organizacional, mas também se considerou na escolha a possibilidade de profissionalização das empresas e, portanto, podendo assumir outras configurações.

Os dados foram coletados por meio de entrevista com o controller das empresas. Procurou-se entender o funcionamento da área organizacional controladoria, sua posição hierárquica, missão, funções, artefatos, forma de relacionamento com outras áreas e com seus funcionários. Dessa maneira, verificaram-se aspectos culturais existentes nessa área organizacional e efetuou-se uma classificação nos tipos de culturas propostos por Trompenaars (1994).

Utilizaram-se as sete dimensões (D) evidenciadas no Quadro 1 da plataforma teórica do estudo para efetuar a classificação nos tipos de culturas propostos por Trompenaars (1994). Para estas dimensões foram atribuídas questões, as quais foram investigadas na entrevista, conforme demonstrado no Quadro 2. 


\begin{tabular}{|c|c|}
\hline $\begin{array}{l}\text { Relação entre } \\
\text { empregados } \\
\mathrm{D}_{1}\end{array}$ & $\begin{array}{l}\text { Média de permanência dos empregados na empresa. Verificação se há } \\
\text { rotatividade ou não. } \\
\text { Verificação se os funcionários estão cientes dos objetivos a serem alcan- } \\
\text { çados na organização. } \\
\text { Forma de convivência dos empregados da controladoria e forma de rela- } \\
\text { cionamento dos empregados da controladoria com os coordenadores e o } \\
\text { controller da empresa. } \\
\text { Reação, comprometimento e participação das pessoas em um processo } \\
\text { de implantação de sistema. }\end{array}$ \\
\hline $\begin{array}{l}\text { Atitude em } \\
\text { relação à } \\
\text { autoridade } \\
\quad \mathrm{D}_{2}\end{array}$ & $\begin{array}{l}\text { Interferência dos membros da família na controladoria. } \\
\text { Subordinação da controladoria. } \\
\text { Áreas organizacionais em que a controladoria possui algum grau de par- } \\
\text { ticipação e a forma dessa participação. } \\
\text { Poder de tomada de decisão dos coordenadores da controladoria. }\end{array}$ \\
\hline $\begin{array}{l}\text { Formas de } \\
\text { pensamento e } \\
\text { aprendizado } \\
\quad \mathrm{D}_{3}\end{array}$ & $\begin{array}{l}\text { Motivação para a criação da controladoria. } \\
\text { Participação da controladoria na tomada de decisão. } \\
\text { Áreas subordinadas à controladoria. } \\
\text { Missão da controladoria. } \\
\text { Objetivos da controladoria. } \\
\text { Forma de acesso e consolidação dos dados entre matriz/filiais. } \\
\text { Áreas de abrangência da controladoria. } \\
\text { Funções e atividades desempenhadas pela controladoria. } \\
\text { Padronização nos procedimentos adotados pela controladoria. } \\
\text { Formação acadêmica dos funcionários e coordenadores da controladoria. } \\
\text { Constatação se há pessoas aptas a substituir uma as outras. }\end{array}$ \\
\hline $\begin{array}{l}\text { Atitudes em } \\
\text { relação às } \\
\text { pessoas } \mathrm{D}_{4}\end{array}$ & $\begin{array}{l}\text { Cargos ocupados pelos membros da família. } \\
\text { Critérios utilizados para promover alguém a um cargo superior ou outra } \\
\text { função. } \\
\text { Forma de seleção dos funcionários da controladoria e responsável pela } \\
\text { decisão. }\end{array}$ \\
\hline $\begin{array}{l}\text { Formas de } \\
\text { mudança } \mathrm{D}_{5}\end{array}$ & $\begin{array}{l}\text { Responsável pela ideia da criação da controladoria. } \\
\text { Responsáveis pela decisão do uso dos artefatos. } \\
\text { Responsável por mudanças na área organizacional controladoria. }\end{array}$ \\
\hline $\begin{array}{l}\text { Formas de } \\
\text { motivação e } \\
\text { recompensa } \mathrm{D}_{6}\end{array}$ & Forma de motivação e recompensa. \\
\hline $\begin{array}{l}\text { Reprovação e } \\
\text { resolução de } \\
\text { conflitos } \mathrm{D}_{7}\end{array}$ & $\begin{array}{l}\text { Forma de solução de eventuais conflitos. } \\
\text { Maneira como as críticas são expostas e quem as faz. }\end{array}$ \\
\hline
\end{tabular}

Quadro 2: Relação das dimensões e das questões pesquisadas

Fonte: Elaborado pelos autores 
$\mathrm{Na}$ análise dos dados, desenvolveu-se um modelo apoiado nas ideias desenvolvidas por Trompenaars (1994) para incrementar o entendimento da classificação nas dimensões das tipologias de cultura organizacional propostas, além de visualizar e quantificar os resultados obtidos no questionário utilizado. O ferramental matemático utilizado no desenvolvimento não vai além de simples artifícios advindos da geometria analítica, que sustentam a técnica que se apresenta abaixo. Os resultados obtidos podem ser verificados nas tabelas constantes na descrição e análise dos dados.

Como principal limitação do estudo, destaca-se que os dados da pesquisa não podem ser generalizados, ou seja, restringem às empresas pesquisadas por meio do estudo multicasos. Outra limitação é que a pesquisa abrangeu uma tipologia de cultura existente na literatura, mas há outras tipologias que podem evidenciar aspectos culturais da área organizacional controladoria das empresas. Uma terceira limitação refere-se à subjetividade presente na classificação nos tipos de cultura propostas por Trompenaars (1994) a partir das respostas das empresas, já que envolve interpretações e decodificações pessoais por parte do pesquisador.

\section{Descrição e Análise dos Dados}

Na descrição e análise dos dados, primeiramente apresentam-se a caracterização das empresas pesquisadas e o perfil dos respondentes da pesquisa. Após, demonstra-se a classificação do tipo de cultura conforme a tipologia de Trompenaars (1994) na área organizacional de controladoria das empresas pesquisadas.

\subsection{Caracterização das Empresas Pesquisadas}

Apresenta-se no Quadro 3 o perfil das empresas pesquisadas, reportando o início das atividades, mercado de atuação, média de faturamento dos últimos três anos, número de empregados e nível de governança corporativa. 


\begin{tabular}{|c|c|c|c|}
\hline Características & Empresa A & Empresa B & Empresa C \\
\hline Início das atividades & 1880 & 1926 & 1950 \\
\hline Mercado de Atuação & Interno e Externo & Interno e Externo & Interno e Externo \\
\hline Média de Faturamento Anual & $\mathrm{R} \$ 447.144$ milhões & $\mathrm{R} \$ 363.081$ milhões & $\mathrm{R} \$ 189.700$ milhões \\
\hline Número de Empregados & 4.700 & 4.700 & 2.359 \\
\hline Nível de Governança & Novo Mercado & Não possui & Não possui \\
\hline
\end{tabular}

Quadro 3: Caracterização das empresas pesquisadas

Fonte: Dados da pesquisa

Verifica-se no Quadro 3 que todas as empresas pesquisadas atuam no mercado interno e externo. Apenas a empresa A participa de um nível de governança corporativa, o Novo Mercado. A empresa mais nova é a $\mathrm{C}$, que já está há 59 anos no mercado, e a mais antiga é a empresa $\mathrm{A}$, existente desde 1880.

Constata-se que as empresas $\mathrm{A}$ e $\mathrm{B}$ possuem o mesmo número de funcionários, 4.700 trabalhadores. Enquanto a empresa $\mathrm{C}$ possui 2.359. O número de funcionários da empresa $\mathrm{C}$ é de uma unidade fabril, sendo esta coligada de uma companhia de capital aberto. Já os dados dos funcionários das demais são consolidados, considerando todas as unidades da empresa.

\subsection{Perfil dos Respondentes da Pesquisa}

Demonstra-se no Quadro 4 o perfil dos respondentes, suas funções denominadas na empresa, tempo na função, idade e formação acadêmica.

\begin{tabular}{|c|c|c|c|}
\hline Questões & Empresa A & Empresa B & Empresa C \\
\hline Função & Controller & Gerente de Controladoria & Controller \\
\hline Tempo na função & 6 meses & 2 anos & 5 anos \\
\hline Idade & 41 anos & 46 anos & 43 anos \\
\hline Graduação & Ciências Contábeis & Ciências Contábeis & Ciências Contábeis \\
\hline Pós-Graduação & Finanças. Controladoria. & Não possui & Não possui \\
\hline
\end{tabular}

Quadro 4: Perfil dos respondentes

Fonte: Dados da pesquisa 
Constata-se no Quadro 4 que é possível encontrar algumas semelhanças entre os entrevistados: todos os três são formados em ciências contábeis, praticamente possuem a mesma idade, e suas funções na organização têm denominações assemelhadas.

Uma diferença encontrada refere-se ao tempo na função. Na Empresa A, a pessoa que exerce a função de controller está no cargo há seis meses, demonstrando que esta área organizacional sofreu mudanças recentemente. Na Empresa B, a pessoa exerce a função de controller há dois anos, entretanto, trabalha na organização há 18 anos. Na Empresa C, a pessoa que está exercendo a função de responsável pela controladoria o faz há cinco anos.

\subsection{Tipo de Cultura Prevalecente em Cada Dimensão da Tipologia de Trompenaars (1994)}

O primeiro procedimento adotado para identificar o tipo de cultural predominante em cada dimensão proposta por Trompenaars (1994) foi enquadrar as respostas dos entrevistados em algum dos quatro tipos culturais, de acordo com as características verificadas no referencial teórico. Em determinadas respostas, há características de mais de um tipo de cultura, nesses casos houve a classificação em todos os tipos em que se enquadravam. O Quadro 5 evidencia a classificação das respostas das empresas por tipo de cultura e dimensão.

\begin{tabular}{|c|c|c|c|c|c|c|c|c|c|c|c|c|c|}
\hline \multirow[b]{2}{*}{ Dimensões } & \multirow{2}{*}{$\begin{array}{c}\text { Tipo de Cultura } \\
\text { Empresas }\end{array}$} & \multicolumn{3}{|c|}{ Familiar } & \multicolumn{3}{|c|}{$\begin{array}{l}\text { Torre } \\
\text { Eiffel }\end{array}$} & \multicolumn{3}{|c|}{$\begin{array}{c}\text { Míssil } \\
\text { Guiado }\end{array}$} & \multicolumn{3}{|c|}{ Incubadora } \\
\hline & & $\mathbf{A}$ & B & $\mathrm{C}$ & $\mathbf{A}$ & B & $\mathrm{C}$ & $\mathbf{A}$ & B & $\mathrm{C}$ & $\mathbf{A}$ & B & $\mathrm{C}$ \\
\hline \multirow{4}{*}{ 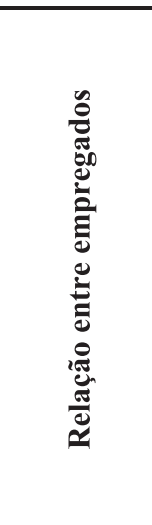 } & $\begin{array}{l}\text { Média de permanência dos empregados } \\
\text { na empresa. Verificação se há } \\
\text { rotatividade ou não. }\end{array}$ & $\mathrm{X}$ & $\mathrm{X}$ & $\mathrm{X}$ & & & & & & & & & \\
\hline & $\begin{array}{l}\text { Verificação se os funcionários estão } \\
\text { cientes dos objetivos a serem alcançados } \\
\text { na organização. }\end{array}$ & & & & & $\mathrm{X}$ & $\mathrm{X}$ & $\mathrm{X}$ & & & & & \\
\hline & $\begin{array}{l}\text { Forma de convivência dos empregados } \\
\text { da controladoria e forma de } \\
\text { relacionamento dos empregados da } \\
\text { controladoria com os coordenadores e o } \\
\text { controller da empresa. }\end{array}$ & $\mathrm{X}$ & & $\mathrm{X}$ & & & & & $\mathrm{X}$ & & $\mathrm{X}$ & & $\bar{X}$ \\
\hline & $\begin{array}{l}\text { Reação, comprometimento } \\
\text { participação d a pessoa em um processo } \\
\text { de implantação de sistema. }\end{array}$ & & & & & & $\mathrm{X}$ & $\mathrm{X}$ & $\mathrm{X}$ & & & & \\
\hline
\end{tabular}




\begin{tabular}{|c|c|c|c|c|c|c|c|c|c|c|c|c|c|}
\hline \multirow{4}{*}{ 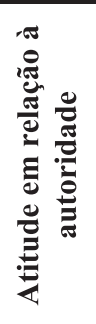 } & $\begin{array}{l}\text { Interferência dos membros da família na } \\
\text { controladoria. }\end{array}$ & $\mathrm{X}$ & & $\mathrm{X}$ & & $\mathrm{X}$ & & & & & & & \\
\hline & Subordinação da controladoria. & & & & $\mathrm{X}$ & $\mathrm{X}$ & & & & $\mathrm{X}$ & & & \\
\hline & $\begin{array}{l}\text { Áreas organizacionais em que a } \\
\text { controladoria possui algum grau de } \\
\text { participação e forma dessa participação. }\end{array}$ & & & & & $\mathrm{X}$ & $\mathrm{X}$ & $\mathrm{X}$ & & & $\mathrm{X}$ & & \\
\hline & $\begin{array}{l}\text { Poder de tomada de decisão dos } \\
\text { coordenadores da controladoria. }\end{array}$ & $\mathrm{X}$ & $\mathrm{X}$ & $\mathrm{X}$ & $\mathrm{X}$ & & & & & & & & \\
\hline \multirow{11}{*}{ 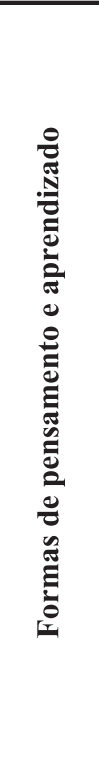 } & $\begin{array}{l}\text { Motivação para a criação da } \\
\text { controladoria. }\end{array}$ & & & & & & & $\mathrm{X}$ & $\mathrm{X}$ & $\mathrm{X}$ & & & \\
\hline & $\begin{array}{l}\text { Participação da controladoria na tomada } \\
\text { de decisão. }\end{array}$ & & $\mathrm{X}$ & & $\mathrm{X}$ & $\mathrm{X}$ & $\mathrm{X}$ & $\mathrm{X}$ & & $\mathrm{X}$ & $\mathrm{X}$ & & $\mathrm{X}$ \\
\hline & Áreas subordinadas à controladoria. & & & & & & & $\mathrm{X}$ & $\mathrm{X}$ & $\mathrm{X}$ & & & \\
\hline & Missão da controladoria. & & & & & & & & & & $\mathrm{X}$ & $\mathrm{X}$ & $X$ \\
\hline & Objetivos da controladoria. & & & & $\mathrm{X}$ & $\mathrm{X}$ & & $\mathrm{X}$ & & $\mathrm{X}$ & & & \\
\hline & $\begin{array}{l}\text { Forma de acesso e consolidação dos } \\
\text { dados entre matriz/filiais. }\end{array}$ & & & & $\mathrm{X}$ & $\mathrm{X}$ & & & & $\mathrm{X}$ & & & \\
\hline & Áreas de abrangência da controladoria. & & & & & & & $\mathrm{X}$ & $\mathrm{X}$ & $\mathrm{X}$ & & & \\
\hline & $\begin{array}{l}\text { Funções e atividades desempenhadas } \\
\text { pela controladoria. }\end{array}$ & & & & $\mathrm{X}$ & $\mathrm{X}$ & $\mathrm{X}$ & $\mathrm{X}$ & $\mathrm{X}$ & $\mathrm{X}$ & & & \\
\hline & $\begin{array}{l}\text { Padronização nos procedimentos } \\
\text { adotados pela controladoria. }\end{array}$ & & $\mathrm{X}$ & & & & & $\mathrm{X}$ & & $\mathrm{X}$ & & & \\
\hline & $\begin{array}{l}\text { Formação acadêmica dos funcionários e } \\
\text { coordenadores da controladoria. }\end{array}$ & & & & & & & $\mathrm{X}$ & $\mathrm{X}$ & $\mathrm{X}$ & & & \\
\hline & $\begin{array}{l}\text { Constatação se há pessoas aptas a } \\
\text { substituir uma às outras. }\end{array}$ & & & & $\mathrm{X}$ & & & & $\mathrm{X}$ & $\mathrm{X}$ & & & \\
\hline \multirow{3}{*}{ 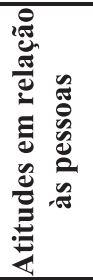 } & $\begin{array}{l}\text { Cargos ocupados pelos membros da } \\
\text { família. }\end{array}$ & $\mathrm{X}$ & $\mathrm{X}$ & $\mathrm{X}$ & & $\mathrm{X}$ & & & & & & & \\
\hline & $\begin{array}{l}\text { Critérios utilizados para promover } \\
\text { alguém a um c argo superior ou outra } \\
\text { função. }\end{array}$ & & & & $\mathrm{X}$ & $\mathrm{X}$ & & & & $\mathrm{X}$ & & & \\
\hline & $\begin{array}{l}\text { Forma de seleção dos funcionários da } \\
\text { controladoria e responsável pela decisão. }\end{array}$ & & & & $\mathrm{X}$ & $\mathrm{X}$ & $\mathrm{X}$ & $\mathrm{X}$ & $\mathrm{X}$ & $\mathrm{X}$ & & & \\
\hline \multirow{3}{*}{ 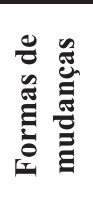 } & $\begin{array}{l}\text { Responsável pela id eia da criação da } \\
\text { controladoria. }\end{array}$ & $\mathrm{X}$ & $\mathrm{X}$ & $\mathrm{X}$ & & & & & & & & & \\
\hline & \begin{tabular}{|l|} 
Responsáveis pela decisão do uso dos \\
artefatos.
\end{tabular} & $\mathrm{X}$ & & $\mathrm{X}$ & & & & & $\mathrm{X}$ & & & & \\
\hline & Responsável por mudanças na área & & & & $\mathrm{X}$ & $\mathrm{X}$ & $\mathrm{X}$ & & & & & & \\
\hline
\end{tabular}

Quadro 5: Classificação por tipo de dimensão e tipo cultura Fonte: Dados da pesquisa

Após a classificação das respostas por tipo de cultura, procedeu-se à análise de verificação do tipo cultural predominante. Para verificar qual tipo cultural prevalece em cada dimensão, a avaliação das empresas consiste em estabelecer em que quadrante ela possui maior presença, considerando-se 
as respostas por elas oferecidas no questionário. Seguindo o esquema desenvolvido por Trompenaars (1994, p. 145), optou-se em utilizar o primeiro quadrante do esquema como sendo a região no plano cartesiano que responde pelas empresas com as características do tipo Míssil Guiado, o segundo quadrante foi destinado às características empresarias do tipo Incubadora, o terceiro quadrante foi destinado às características das empresas do tipo Familiar e o quarto quadrante para as características do tipo empresarial Torre Eiffel.

A rotação dos eixos coordenados permitiu a introdução de escalas sobre os quatro quadrantes propostos. A função $\mathrm{y}=\mathrm{x}$, conhecida matematicamente como reta identidade, atende o primeiro e terceiro quadrantes. Já a função y $=-x$ faz a ligação entre o segundo e o quarto quadrantes. Sobre essas retas foi construída uma escala ordinal que muda segundo a quantidade de questões utilizadas por variável. A dimensão Formas de Pensamento e Aprendizado (D3), por exemplo, possui uma escala de 11 possibilidades (11 questões), ou seja, de zero (nenhuma resposta no quadrante) até um total de 11, que implica na presença de todos os atributos daquele tipo de empresa. As dimensões Relação com Empregados (D1) e Atitude com Relação à Autoridade (D2) possuem quatro questões, logo, em cada quadrante haverá uma escala de zero a quatro. As dimensões Atitudes em Relação às Pessoas (D4) e Formas de Mudança (D5) possuem três questões. A dimensão Reprovação e Resolução de Problemas (D7) possui duas questões e o item Formas de Motivação e Recompensa (D6) com apenas uma única questão, sendo assim de possibilidade binária.

A partir da pontuação em cada quadrante, construiu-se a figura relativa às respostas obtidas. Assim, em havendo pontuação nos quatro quadrantes, a figura formada foi um polígono de quatro lados, pontuando apenas em três quadrantes obteve-se um triângulo. Caso apenas dois quadrantes tivessem resposta, foi construída a reta que liga os dois pontos-resposta. No caso da dimensão binária (Formas de Motivação e Recompensa), apenas um quadrante foi utilizado. Contudo, houve casos em que as características não foram unívocas, ou seja, há casos em que o número de respostas ultrapassa o número de possibilidades, fato esse que não inviabilizou a técnica, mas, sim, acrescentou informação para o entendimento.

O método caracteriza-se por calcular a área ocupada pelas respostas aos questionários em cada quadrante. $\mathrm{O}$ modelo pode ser entendido como sendo um sistema de classificação difuso, embora não seja essa sua preten- 
são, mas tão simplesmente em se apoiar nas ideias desenvolvidas por Trompenaars (1994) para incrementar o entendimento da classificação sugerida e visualizar e quantificar os resultados obtidos no questionário utilizado. O ferramental matemático utilizado em seu desenvolvimento não vai além de simples artifícios advindos da geometria analítica e que sustentam a técnica que se apresenta. Por último, e não menos importante, está a vantagem do método em estabelecer uma classificação que vai além da simples contagem, ou formação de médias, permitindo, segundo o esquema estudado, avaliar tendências de uma empresa. Assim, classificações idênticas em, por exemplo, três quadrantes, podem ser desempatadas pelo método, visto que ele se apoia na ideia de área utilizada, ou seja, não se trata de uma medida linear.

Para exemplificar, toma-se a Empresa B na dimensão Formas de Pensamento e Aprendizado (D3), com 11 possibilidades em cada quadrante. Geometricamente a representação pode ser visualizada conforme Figura 1.

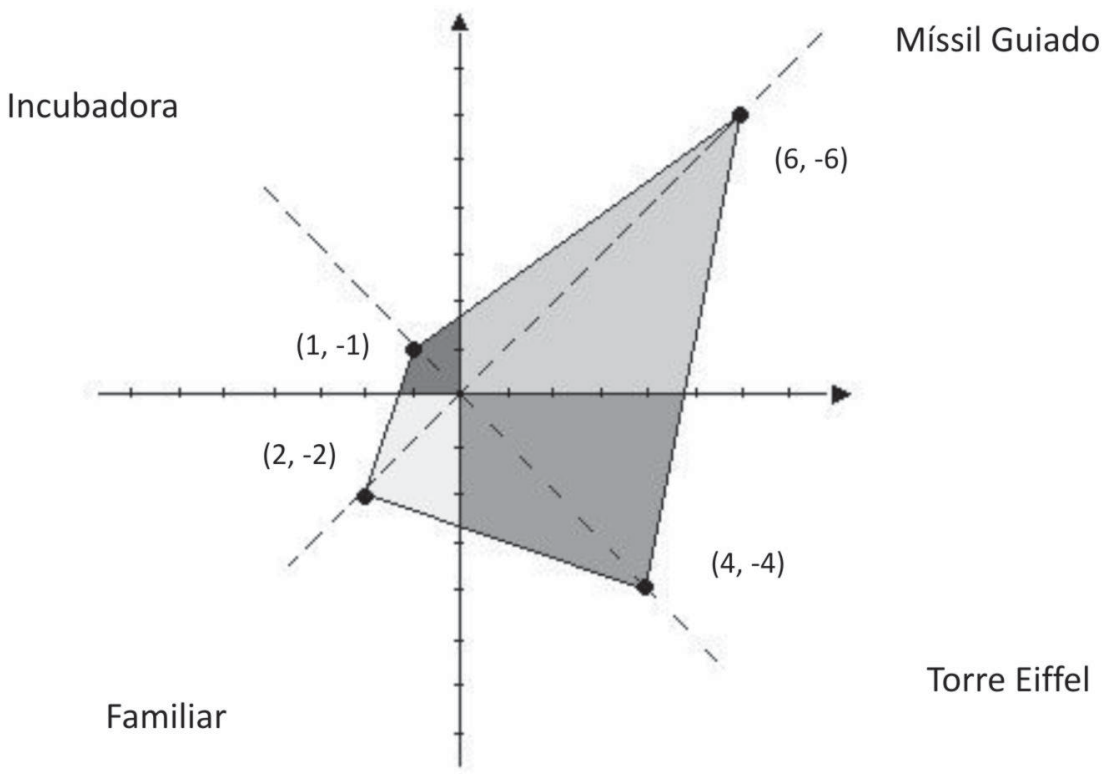

Figura 1: Representação Gráfica da Empresa-B segundo a dimensão D3 Fonte: Elaborado pelos autores

A Figura 1 representa as respostas dadas pela Empresa B na entrevista em sua dimensão D3. Ela possui seis características como sendo uma empre- 
sa do tipo Míssil Guiado (M), uma característica no quadrante Incubadora (I), duas características no quadrante Familiar $(\mathrm{F})$ e quatro características no quadrante Torre Eiffel (T).

Utilizando-se de ferramentas de cálculo de área, advindas da geometria, verificou-se que o polígono de vértices $\mathrm{M}=(6,6) ; \mathrm{I}=(-1,1) ; \mathrm{F}=(-2,-2)$ e $\mathrm{T}=(4,-4)$ possui área de 42 unidades (u.a.). Desse total, 19,54 u.a. se localizam no primeiro quadrante, ou seja, $46,5 \%$ em valores relativos. No segundo quadrante, que é o das empresas do tipo Incubadora, a área do polígono é de apenas 1,53 u.a., o que equivale a 3,6\% do total. No terceiro quadrante, a presença do polígono é de 6 u.a., que representam 14,4\%. Por último, o quarto quadrante possui 14,93 u.a., o que representa $35,5 \%$ do total.

De forma simplificada, pode-se afirmar que a Empresa $\mathrm{B}$ pode ser caracterizada como sendo 46,5\% do tipo Míssil Guiado, 35,5\% como Torre Eiffel, 14,4\% como Familiar e apenas 3,6\% do tipo Incubadora.

Dessa maneira foram realizados os enquadramentos nos tipos culturais em cada dimensão relacionada. Localizaram-se os pontos no plano cartesiano no tipo cultural classificado a cada questão, constituindo-se assim os vértices da figura. Em seguida, traçaram-se retas para possibilitar os cálculos das áreas e assim determinar a porcentagem pertencente a cada tipo de cultura estudada.

Na dimensão Relação entre Empregados (D1), por exemplo, das quatro questões elaboradas, a Empresa $\mathrm{C}$ teve duas questões que se enquadraram no tipo de cultura familiar, duas no tipo de Torre Eiffel e uma no tipo de cultura Incubadora. Nota-se neste caso, que em uma questão houve a classificação em dois tipos de culturas. Prosseguiu-se traçando os pontos no plano cartesiano e as retas, constituindo-se a figura geométrica do triângulo, uma vez que houve a pontuação em apenas três quadrantes (Incubadora, Familiar e Torre Eiffel). Com as retas traçadas, procedeu-se ao cálculo das áreas e da porcentagem de predominância em cada quadrante ou tipo cultural.

Na dimensão Atitude em Relação à Autoridade (D2), a Empresa A teve duas questões enquadradas como Familiar, outras duas como Torre Eiffel, uma em Míssil Guiado e uma em Incubadora. Neste caso, houve a pontuação nos quatro quadrantes, constituindo-se assim a figura geométrica de um polígono. Da mesma forma, calculou-se a área do polígono e verificou-se a porcentagem de participação do total da área em cada quadrante. E assim sucessivamente foram realizados os cálculos a cada dimensão e por empresa. De modo geral e sucinto, os resultados obtidos podem ser verificados nas tabelas constantes na descrição e análise dos dados. 


\subsection{Enquadramento na Tipologia de Trompenaars (1994)}

Apresenta-se a seguir o enquadramento das respostas nos tipos de cultura propostos por Trompenaars (1994) da área organizacional controladoria das empresas pesquisadas, de acordo com as áreas calculadas em cada dimensão proposta.

\subsection{Relação entre Empregados}

Demonstra-se na Tabela 1 a classificação geral das empresas referente à dimensão Relação entre Empregados (D1).

Tabela 1: Classificação geral das empresas na dimensão D1

\begin{tabular}{c|c|c|c|c}
\hline $\begin{array}{c}\text { Classificação } \\
\text { Empresa }\end{array}$ & $\begin{array}{c}\text { Míssil } \\
(\%)\end{array}$ & $\begin{array}{c}\text { Incubadora } \\
(\%)\end{array}$ & $\begin{array}{c}\text { Familiar } \\
(\%)\end{array}$ & $\begin{array}{c}\text { Torre } \\
(\%)\end{array}$ \\
\hline Empresa A & 16,7 & 38,9 & $\mathbf{4 4 , 4}$ & 0,0 \\
\hline Empresa B & $\mathbf{4 4 , 4}$ & 0,0 & 16,7 & 38,9 \\
\hline Empresa C & 0,0 & 11,1 & $\mathbf{5 5 , 6}$ & 33,3 \\
\hline
\end{tabular}

Fonte: Dados da pesquisa

Verifica-se na Tabela 1 que, quanto à dimensão Relação entre Empregados, o tipo predominante de cultura da Empresa A é Familiar, com grande proximidade do tipo Incubadora. Isso demonstra que a forma de convivência dos funcionários da controladoria em geral com o controller da empresa é espontânea, difusa, ou seja, é igualitária, porém, há uma hierarquia, respeitando sempre a pessoa de maior autoridade.

Enquanto na empresa $\mathrm{B}$, o tipo predominante é míssil guiado com proximidade na torre Eiffel, demonstrando que há uma cultura igualitária no quesito relação entre empregados, uma vez que abrange tarefas específicas. $\mathrm{Na}$ Empresa C, há predominância da cultura Familiar com proximidade na Torre Eiffel, ou seja, é uma cultura mais igualitária, mas há uma hierarquia.

Constata-se nesta dimensão que, em geral, a cultura Familiar predomina ficando próxima da cultura Torre Eiffel.

\subsubsection{Atitude em Relação à Autoridade}

Evidencia-se na Tabela 2 a classificação geral das empresas referente à dimensão Atitude em Relação à Autoridade (D2). 
Tabela 2: Classificação geral das empresas na dimensão D2

\begin{tabular}{c|c|c|c|c}
\hline Classificação & $\begin{array}{c}\text { Míssil } \\
(\%)\end{array}$ & $\begin{array}{c}\text { Incubadora } \\
(\%)\end{array}$ & $\begin{array}{c}\text { Familiar } \\
(\%)\end{array}$ & $\begin{array}{c}\text { Torre } \\
(\%)\end{array}$ \\
\hline Empresa & 13,0 & 13,0 & $\mathbf{3 7 , 0}$ & $\mathbf{3 7 , 0}$ \\
\hline Empresa A & 0,0 & 0,0 & 25,1 & $\mathbf{7 4 , 9}$ \\
\hline Empresa B & 16,7 & 0,0 & $\mathbf{4 4 , 4}$ & 38,9 \\
\hline
\end{tabular}

Fonte: Dados da pesquisa

Constata-se na Tabela 2 que a Empresa A possui a mesma proporção de cultura Familiar quanto de cultura Torre Eiffel na dimensão Atitude em Relação à Autoridade. Demonstra-se, assim, que em alguns quesitos o poder de decisão concentra-se na pessoa de maior autoridade, que em alguns casos recai no membro familiar e que a subordinação nesta empresa é claramente racional.

A Empresa B tem a predominância da cultura Torre Eiffel com proximidade na Familiar. Nela há uma burocracia formal e as relações referentes aos itens de interferência dos membros da família na controladoria, à subordinação da controladoria, às áreas em que a controladoria possui algum grau de participação e ao poder de tomada de decisão dos coordenadores da controladoria são impessoais.

A Empresa $\mathrm{C}$ tende a ser mais Familiar, com muita proximidade do tipo Torre Eiffel, igualando, dessa forma, com a Empresa A. Evidencia-se nos casos expostos que há grande proximidade entre a cultura Familiar e Torre Eiffel.

\subsubsection{Formas de Pensamento e Aprendizado}

Demonstra-se na Tabela 3 a classificação geral das empresas referente à dimensão Formas de Pensamento e Aprendizado (D3.).

Tabela 3: Classificação geral das empresas na dimensão D3

\begin{tabular}{c|c|c|c|c}
\hline Classificação & $\begin{array}{c}\text { Míssil } \\
(\%)\end{array}$ & $\begin{array}{c}\text { Incubadora } \\
(\%)\end{array}$ & $\begin{array}{c}\text { Familiar } \\
(\%)\end{array}$ & $\begin{array}{c}\text { Torre } \\
(\%)\end{array}$ \\
\hline Empresa & $\mathbf{6 3 , 0}$ & 9,5 & 0,00 & 27,5 \\
\hline Empresa A & $\mathbf{4 6 , 5}$ & 3,6 & 14,4 & 35,5 \\
\hline Empresa B & $\mathbf{8 3 , 4}$ & 8,3 & 0,00 & 8,3 \\
\hline
\end{tabular}

Fonte: Dados da pesquisa

Evidencia-se na Tabela 3 que há predominância da cultura Míssil Guiado em todas as três empresas quanto à dimensão Formas de Pensamento $e$ 
Aprendizado. Isso demonstra que o órgão controladoria das empresas é profissional, prático e interdisciplinar, com ênfase nos objetivos estratégicos da organização. Verifica-se também que a cultura Torre Eiffel está próxima do tipo Míssil Guiado nos casos das Empresa $\mathrm{A}$ e B, enquanto na $\mathrm{C}$, há tanto a proximidade da Torre Eiffel quanto Incubadora.

\subsubsection{Atitudes em Relação às Pessoas}

Expõe-se na Tabela 4 a classificação geral das empresas referente à dimensão Atitudes em Relação às Pessoas (D4).

Tabela 4: Classificação geral das empresas na dimensão D4

\begin{tabular}{c|c|c|c|c}
\hline Classificação & $\begin{array}{c}\text { Míssil } \\
(\%)\end{array}$ & $\begin{array}{c}\text { Incubadora } \\
(\%)\end{array}$ & $\begin{array}{c}\text { Familiar } \\
(\%)\end{array}$ & $\begin{array}{c}\text { Torre } \\
(\%)\end{array}$ \\
\hline Empresa & 16,8 & 0,0 & 16,8 & $\mathbf{6 6 , 4}$ \\
\hline Empresa A & 12,5 & 0,0 & 12,5 & $\mathbf{7 5 , 0}$ \\
\hline Empresa C & $\mathbf{4 4 , 4}$ & 0,0 & 1,67 & 38,9 \\
\hline
\end{tabular}

Fonte: Dados da pesquisa

Verifica-se na Tabela 4 que há predominância da cultura Torre Eiffel nas Empresas A e B, com proximidades idênticas tanto da cultura Familiar quanto Míssil Guiado. Infere-se que essas empresas possuem características semelhantes entre si. Demonstra-se que as pessoas são promovidas e/ou contratadas principalmente por suas qualificações e que há padronização para seleção de pessoas. Constata-se também que a cultura predominante da Empresa C é Míssil Guiado com proximidade na Torre Eiffel.

\subsubsection{Formas de Mudanças}

Demonstra-se na Tabela 5 a classificação geral das empresas referente à dimensão Formas de Mudanças (D5).

Tabela 5: Classificação geral das empresas na dimensão D5

\begin{tabular}{c|c|c|c|c}
\hline Classificação & $\begin{array}{c}\text { Míssil } \\
(\%)\end{array}$ & $\begin{array}{c}\text { Incubadora } \\
(\%)\end{array}$ & $\begin{array}{c}\text { Familiar } \\
(\%)\end{array}$ & $\begin{array}{c}\text { Torre } \\
(\%)\end{array}$ \\
\hline Empresa & 0,00 & 0,0 & $\mathbf{7 5 , 9}$ & 24,1 \\
\hline Empresa A & 25,0 & 0,0 & 25,0 & $\mathbf{5 0 , 0}$ \\
\hline Empresa B & 0,00 & 0,0 & $\mathbf{7 5 , 9}$ & 24,1 \\
\hline
\end{tabular}

Fonte: Dados da pesquisa 
Constata-se na Tabela 5 que predomina a cultura Familiar nas Empresas $\mathrm{A}$ e $\mathrm{C}$, com proximidade na Torre Eiffel, referente às formas de mudança. Isso significa dizer que os membros da família são responsáveis pela criação da controladoria e pelo uso dos artefatos. Quanto às mudanças no órgão controladoria, há uma divisão de trabalho em que cada um é responsável pela execução de seu papel. Na Empresa B há predominância da cultura Torre Eiffel, com proximidade tanto na Familiar quanto no Míssil Guiado.

\subsubsection{Formas de Motivação e Recompensa}

Apresenta-se na Tabela 6 a classificação geral das empresas referente à dimensão Formas de Motivação e Recompensa (D6).

Tabela 6: Classificação geral das empresas na dimensão D6

\begin{tabular}{c|c|c|c|c}
\hline Classificação & $\begin{array}{c}\text { Míssil } \\
(\%)\end{array}$ & $\begin{array}{c}\text { Incubadora } \\
(\%)\end{array}$ & $\begin{array}{c}\text { Familiar } \\
(\%)\end{array}$ & $\begin{array}{c}\text { Torre } \\
(\%)\end{array}$ \\
\hline Empresa & $\mathbf{1 0 0 , 0}$ & 0,0 & 0,0 & 0,0 \\
\hline Empresa A & 0,0 & 0,0 & 0,0 & $\mathbf{1 0 0 , 0}$ \\
\hline Empresa C & 0,0 & 0,0 & $\mathbf{1 0 0 , 0}$ & 0,0 \\
\hline
\end{tabular}

Fonte: Dados da pesquisa

Verifica-se que nesta dimensão há predominância em diferentes tipos de cultura nas empresas. A Empresa A é 100\% Míssil Guiado, por possuir o método de remuneração por desempenho. A Empresa B também é Míssil Guiado, mas por existir promoção por uma posição melhor. Já a Empresa C é Familiar, pelo fato de que os empregados são motivados por meio de elogios, havendo uma satisfação intrínseca em ser respeitado.

\subsubsection{Reprovação e Resolução de Conflitos}

Apresenta-se na Tabela 7 a classificação geral das empresas referente à dimensão Reprovação e Resolução de Conflitos (D7).

Tabela 7: Classificação geral das empresas na dimensão D7

\begin{tabular}{c|c|c|c|c}
\hline Classificação & $\begin{array}{c}\text { Míssil } \\
(\%)\end{array}$ & $\begin{array}{c}\text { Incubadora } \\
(\%)\end{array}$ & $\begin{array}{c}\text { Familiar } \\
(\%)\end{array}$ & $\begin{array}{c}\text { Torre } \\
(\%)\end{array}$ \\
\hline Empresa & $\mathbf{6 6 , 7}$ & 0,0 & 33,3 & 0,0 \\
\hline Empresa A & $\mathbf{1 0 0 , 0}$ & 0,0 & 0,0 & 0,0 \\
\hline Empresa B & 25,0 & 0,0 & 25,0 & $\mathbf{5 0 , 0}$ \\
\hline
\end{tabular}

Fonte: Dados da pesquisa 
Demonstra-se na Tabela 7 que há predominância da cultura Míssil Guiado com proximidade da Familiar na Empresa A, referente a forma de reprovação e resolução de conflitos. Isso significa dizer que as críticas e a forma de solução de eventuais conflitos são construtivas, relacionada à tarefa apenas e quem geralmente as faz é o controller. A Empresa B é totalmente Míssil Guiado neste quesito. Na Empresa C predomina Torre Eiffel, por não existirem praticamente conflitos e exposição de críticas, mas há características tanto de Familiar quanto de Míssil Guiado.

\section{Conclusões}

O estudo objetivou identificar os tipos de análise da cultura organizacional de Trompenaars (1994) prevalecentes na área de controladoria em empresas familiares do ramo têxtil. Pesquisa descritiva, com abordagem quantitativa, foi realizada por meio de estudo de multicasos. Foram avaliadas três empresas do ramo têxtil de origem familiar, que possuem a área organizacional de controladoria formalmente constituída.

Constatou-se que há forte presença da cultura Familiar entre as empresas pesquisadas nas dimensões: Relação entre Empregados, Atitude em Relação à Autoridade, Formas de Mudanças, Formas de Motivação e Recompensa. A média de permanência dos empregados na controladoria pode ser considerada de longo prazo, não havendo rotatividade nos cargos e nem nas funções, e sua forma de convivência é por meio de relações difusas. Verificou-se ainda que os membros da família possuem interferência na área organizacional controladoria e que os coordenadores desse órgão sempre se reportam ao controller para a tomada de decisão. Evidenciou-se ainda que o responsável pela criação da controladoria e pelos usos de seus artefatos são as pessoas de maior autoridade, geralmente membros da família, ocupando o cargo de presidente e/ou conselho de administração nas organizações. A forma de recompensa e motivação para seus empregados é por meio de satisfação intrínseca em ser amado e respeitado.

Quanto à cultura do tipo Torre Eiffel, predominou nas dimensões: Atitude em Relação à Autoridade, Atitudes em Relação às Pessoas, Formas de Mudança, Formas de Motivação e Recompensa, Reprovação e Resolução de Conflitos. Verificou-se também que na empresa em que o cargo de presidente não é ocupado por um membro da família, mas por alguém devido a sua 
qualificação, não há interferência dos familiares na área organizacional controladoria. Além disso, averiguou-se que a subordinação da controladoria é atribuída às áreas que possuem grande importância nas empresas e que muitas vezes a controladoria participa em outras áreas da organização por meio de normatização e procedimentos. Constatou-se também que as pessoas são selecionadas para trabalhar na área de controladoria dessas empresas por suas qualificações, e que faz parte da função do controller decidir por mudanças dentro desse órgão. Recompensam seus funcionários por meio de promoção a uma posição melhor e também é comum não existir conflitos nessa área da organização em certas entidades. Ressalta-se ainda que a cultura Torre Eiffel fica bem próxima em algumas dimensões predominantes das empresas.

Referente à cultura Míssil Guiado, prevaleceu nas dimensões: Relação entre Empregados, Formas de Pensamento e Aprendizado, Atitudes em Relação às Pessoas, Formas de Motivação e Recompensa, Reprovação e Resolução de Conflitos. Demonstrou-se, assim, que há tarefas específicas na controladoria dessas empresas, visando sempre objetivos compartilhados. Constatou-se também que a maior parte das características da controladoria, seja sua missão, objetivos, funções, áreas de abrangência, entre outros, enquadram-se nesta cultura. Há mais igualdade entre as pessoas do que nas do tipo Torre Eiffel, porém, possuem certo grau de impessoalidade. Verificou-se que a área de controladoria das empresas atua com profissionalismo, é pragmática e enfatiza os objetivos estratégicos da organização. Recompensam seus empregados por meio de remuneração por desempenho e as críticas expostas nessas empresas sempre são construtivas, visando apenas tarefas, e não pessoas.

Constatou-se que a cultura Incubadora não foi predominante em nenhuma das sete dimensões estabelecidas, o que já se esperava, visto que este tipo de cultura geralmente concentra-se em empresas menores. Na seleção das empresas, foram priorizadas familiares do setor têxtil com uma área de controladoria formalizada na estrutura da organização, o que não é comum em empresas de pequeno porte.

Conclui-se que não existe um tipo puro de cultura, conforme fora preconizado na teoria por Trompenaars (1994). Entre as empresas pesquisadas, verificou-se uma mistura da cultura Familiar, cultura Torre Eiffel e Míssil $\mathrm{G}$, uiado. A partir das entrevistas com o controller das empresas pesquisadas observou-se que, embora essas empresas sejam de origem familiar, são alta- 
mente profissionalizadas. Verificou-se também com base nas respostas dos entrevistados que a cultura organizacional influencia fortemente as práticas de controladoria dessas empresas.

Dadas as limitações deste estudo, recomenda-se para futuras pesquisas efetuar uma investigação em empresas não familiares e fazer a comparação dos resultados. Ressalta-se ainda que há várias tipologias de cultura organizacional que podem ser relacionadas com a área organizacional de controladoria, as quais recomenda-se sejam pesquisadas em empresas e os resultados comparados com os achados deste estudo.

\section{Types of Analysis of Trompenaar's (1994) Organizational Culture Prevailing in the Area of Controllership in Family Businesses in Textile Industry}

\section{Abstract}

The study aims to identify the types of analysis of Trompenaar's (1994) organizational culture prevailing in the area of controllership in family businesses in textile industry. Descriptive research was performed, with quantitative and qualitative approach, using a multiple case study. Data were collected through interviews with the controller of the companies. In the four basic culture types suggested by Trompenaars (1994), it is concluded that there isn' $t$ a pure kind, but there is a strong presence of family culture among the companies surveyed in dimensions relationship between employees, attitude in relation to the ways of change, forms of motivation and reward.

Key words: Organizational culture. Trompenaar's types. Controllership.

\section{Referências}

CAMERON, Kim S.; QUINN, Robert E. Diagnosing and changing organizational culture. Reading, MA: Addison Wesley Longman, 1999. 
CERVO, A. L.; BERVIAN, P. A. Metodologia científica. 4. ed. São Paulo: Makron, 1996.

FREITAG, Viviane da Costa; MATTOS, Marinei Abreu; STARKE JUNIOR, Paulo César; CLEMENTE, Ademir. A influência da cultura na adoção das práticas de orçamento e custeio: estudo comparativo entre os APLS de Colombo e Terra Roxa. In: CONGRESSO BRASILEIRO DE CUSTOS, 15., João Pessoa, 2008. Anais... São Leopoldo: ABC, 2008.

LEAL, R. S.; SOUZA, E. E. S.; ROCHA, N. M. F. O papel dos gestores no processo de mudança cultural: o caso de uma fábrica de fertilizantes. In: ENECULT, 4., 2008, Salvador. Anais... Salvador: UFBA, 2008.

MACHADO, D. D. P. N.; CARVALHO, C. E. Tipologias culturais e ambiente organizacional: uma análise conceitual. Latin American Business Review (Binghamton), v. 9, p. 1-22, 2008.

MOSIMANN, C. P.; FISCH, S. Controladoria: seu papel na administração de empresas. 2. ed. São Paulo: Atlas, 1999.

RICHARDSON, R. J. Pesquisa social: métodos e técnicas. 3. ed. São Paulo: Atlas, 1999.

SANTOS, A. R.; ALMEIDA, L. B.; CROZATTI, J. Considerações sobre o processo de institucionalização de área organizacional de controladoria: uma abordagem de interação da visão da psicologia humana, cultura organizacional à teoria institucional. In: ENANPAD, 2007, Rio de Janeiro. Anais ... Rio de Janeiro: ANPAD, 2007.

SCHNEIDER, W. E. Uma alternativa à reengenharia: um plano para fazer a cultura atual da sua empresa funcionar. Rio de Janeiro: Record, 1996.

SCHEIN, E. H. Coming to a new awareness of organizational culture. Separata 2521, v. 25, n. 2, Winter, 1984.

TARIFA, M. R. Cultura organizacional e práticas orçamentárias: um estudo empírico nas maiores empresas do sul do Brasil. 2008. Dissertação (Mestrado em Administração) - Universidade Federal do Paraná, 2008. Disponível em: <http://dspace.c3sl.ufpr.br:8080/dspace/handle/1884/17508>. Acesso em: 26 mar. 2009. 
TARIFA, M. R. Cultura e comportamento organizacional nas práticas de controladoria empresarial: estudo de caso em uma companhia de café solúvel do norte do Paraná. In: Congresso USP de Controladoria e Contabilidade, 7., 2007, São Paulo. Anais ... Disponível em: < http:// www.congressoeac.locaweb.com.br/artigos72007/384.pdf>. Acesso em: 27 mar. 2009.

TRIVIÑOS, A. N. S. Introdução à pesquisa em ciências sociais: a pesquisa qualitativa em educação. São Paulo: Atlas, 1987.

TROMPENAARS, F. Nas ondas da cultura: como entender a diversidade cultural nos negócios. São Paulo: Educator, 1994. 